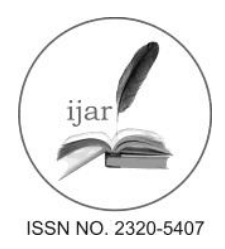

Journal homepage:http://www.journalijar.com

Journal DOI:10.21474/IJAR01

INTERNATIONAL JOURNAL

OF ADVANCED RESEARCH

RESEARCH ARTICLE

\title{
ABSORPTION STUDIES OF CREATININE USING SINGLE-REAGENT AND SINGLE WAVE LENGTH METHOD BY OPTICAL INTERFERENCE WAVELENGTH FILTER.
}

Sreedhar MALLETI.

Associate Professor of Electronics and communications Engineering,Indo-American Institutions Technical Campus, Anakapalli, Visakhapatnam, Andhra Pradesh, India.

\section{Manuscript Info}

Manuscript History:

Received: 16 March 2016

Final Accepted: 19 April 2016

Published Online: May 2016

Key words:

absorption creatinine endpoint

photometer

*Corresponding Author

Sreedhar MALLETI.

\section{Abstract}

Accurate measurement of Creatinine is very essential in order to pre diagnosis the renal functioning of human body. In this paper we introduced the measurement of creatinine by means of studying its equivalent absorption with the interaction of wavelength of light using endpoint method with the help of photometer.

Copy Right, IJAR, 2016, All rights reserved.

\section{Introduction:-}

Creatinine reacts with Picric Acid in an alkaline medium to form an Orange colored complex. The rate of formation of this complex is measured by reading the change in absorbance at $505 \mathrm{~nm}$ in a selected interval of time and is proportional to the concentration of Creatinine. The reaction time and the concentration of Picric Acid and Sodium Hydroxide have been optimized to avoid interference from ketoacids. These measurements are based on the reaction between Creatinine and Picric Acid which yields orange colored complex consequently measured by a photometer. However these measurements plays major role in renal system function which deals with the correct identification of (GFR) Glomerular filtration rate [7].Glomerular filtration rate (GFR) can be used to asses renal function. There are two types, actual and estimated GFR. In actual GFR, the equation UV/P is used where $U$ and $P$ are the concentrations of creatinine in the urine and plasma respectively, with $\mathrm{V}$ being the amount of urine produced in 1 minute. Since creatinine levels vary during the day, for $\mathrm{V}$ and $\mathrm{U}$ to be accurate, urine needs to be collected over 24 hours. This makes the test time consuming for the patient. To avoid the 24 hour collection of urine, an estimated GFR (eGFR) can be used in which only the plasma creatinine is used. Estimated GFR can be successfully used to identify patients which would need an actual GFR [7].

\section{Reagents composition:-}

Table 1:-

\begin{tabular}{|l|l|l|l|}
\hline Reagent No. & Reagent & Composition & Concentration \\
\hline 1 & Picrate Reagent & $\begin{array}{l}\text { Picric Acid } \\
\text { Preservative }\end{array}$ & $40 \mathrm{mM} / \mathrm{L} \mathrm{qs}$ \\
\hline 2 & Sodium Hydroxide & Sodium Hydroxide & $200 \mathrm{mM} / \mathrm{L}$ \\
\hline 3 & Creatinine Standard & Creatinine Stabiliser & $2 \mathrm{mg} / \mathrm{dl} \mathrm{qs}$ \\
\hline
\end{tabular}




\section{Working reagent preparation:-}

Prepare Working Reagent by mixing equal volume of Reagent 1 (Picrate Reagent) with Reagent2(Sodium Hydroxide) to make up the desired volume. Mix gently for 2 minutes. Reagent 3 is ready to use.

\section{Reagent storage and stability:-}

\section{Prior to reconstitution:-}

Unopened Reagents 1,2 are stable at Room Temperature $\left(15-30{ }^{\circ} \mathrm{C}\right)$ and reagent 3 is stable at $2-8{ }^{\circ} \mathrm{C}$ until the expiry date mentioned on the container label.

After reconstitution, The "Working Reagent" is stable for 7 days at $2-8^{\circ} \mathrm{C}$.

\section{Equipment and specifications:-}
a. Light source:-
b. Inner Reaction bath window:-
c. Outer Reaction bath window:-
d. lens system and photometer:-This system consists of

9 optical paths with interference filters

Wavelengths: $340 \mathrm{~nm}, 405 \mathrm{~nm}, 450 \mathrm{~nm}, 510 \mathrm{~nm}, 546 \mathrm{~nm}, 578 \mathrm{~nm}, 630 \mathrm{~nm}, 670 \mathrm{~nm}, 700 \mathrm{~nm}$

Half band width: $\leq 12 \mathrm{~nm}$

Measurement range: 0.1-4.0 Abs

Lamp: 12 V 50 VA tungsten-halogen

\section{Experiment lay out:-}

The optical setup is shown in the following fig 1.1consists of the above discussed components such light source (LS1), optical lens system, cuvette for serum sample, primary and secondary interference filters and the photo detector [10].

\section{Methodology:-}

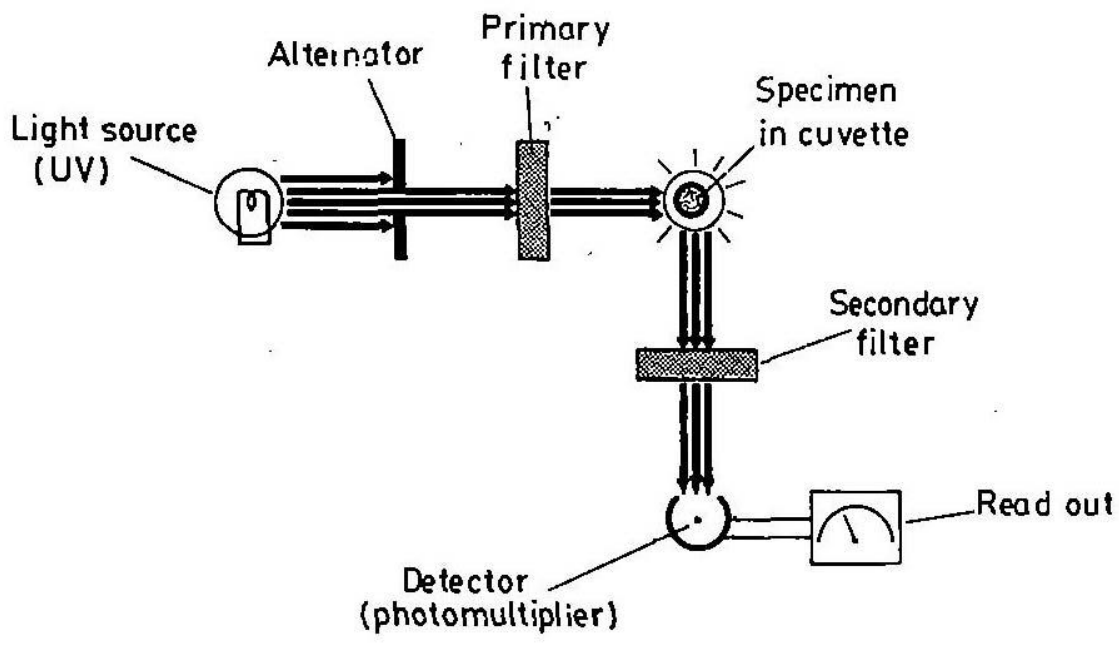

It is purely based on end point reaction. The reaction reaches equilibrium after certain period. Because the equilibrium constant is very large, it can be considered that all substrates have changed into products, and the absorbance of the reaction liquid does not change any more. The absorbance change is proportional to the amount of the product present. In this experiment the time when the reagent is added is $t 1$, the time when the sample is added is $\mathrm{t} 2$, are measured. The reaction starts when they are mixed. At time $\mathrm{t} 3$ the reaction reaches the equilibrium and the absorbance reading is taken. The reaction time is $\mathrm{t} 3-\mathrm{t} 2$. The end point reaction is not subject to such condition changes as enzyme concentration, $\mathrm{pH}$ value and temperature, as long as the changes are not significant enough to affect the reaction time [10]. 
As shown in the above figure, when a parallel monochromatic light beam whose intensity is Io goes through a flow cell (whose length is L) containing a solution (whose concentration is C), some photons are absorbed, and the intensity is attenuated from Io to $\mathrm{I} t$, so the absorbance A of this solution is:

$\mathrm{A}=-\mathrm{Log} \mathrm{It} / \mathrm{I} 0$

Where, It/I0= transmittivity

Calculating the response of the end-point reaction:-

Single -reagent and single wavelength:-

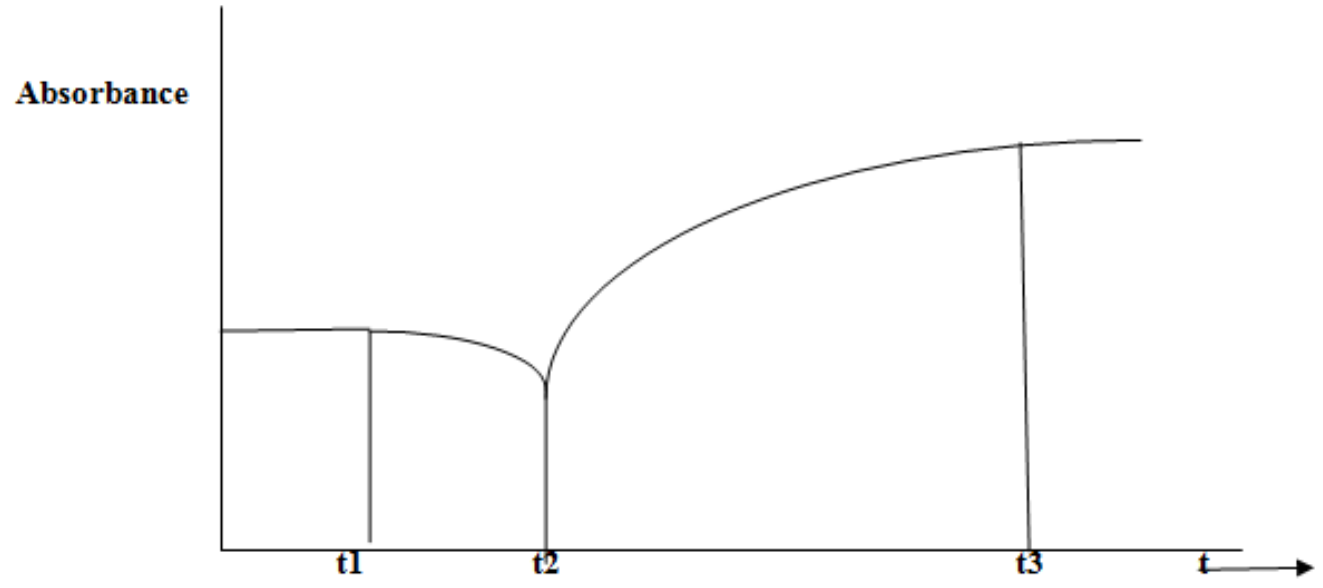

Fig 1.2:- Endpoint reaction with single-regent and single-wavelength.

As shown in the above figure, $\mathrm{t} 1$ is the time when the reagent (volume) is added.t 2 is the time when the sample (volume: $\mathrm{S}$ ) is added. The reaction starts when they are mixed. At $\mathrm{t} 3$ the reaction reaches the equilibrium and the absorbance reading is taken.t3-t 2 is the reaction time.so

$\mathrm{R}=\mathrm{R}_{\mathrm{s}}-\mathrm{R}_{\mathrm{SMPB}}$

Both $R_{s}$, and $R_{S M P B}$ are calculated with the formula $R=A t 3-K 1 X A t 2-1$.

Where,

$\mathrm{R}_{\mathrm{s}}=$ Response of reaction mixture

$\mathrm{R}_{\mathrm{SMPB}}=$ response of sample blank. If the sample blank has not been requested,

$\mathrm{R}_{\mathrm{SMPB}}=0$

At $3=$ Absorbance at $\mathrm{t} 3$

A $\mathrm{t} 2-1=$ Absorbance at the previous point before $\mathrm{t} 2$.

$\mathrm{K} 1=$ Single reagent test volume coefficient, If the start time of reaction is $0, \mathrm{~K} 1=\mathrm{V} /(\mathrm{V}+\mathrm{S})$; otherwise, $\mathrm{K} 1=1$ 


\section{Results of experiment:-}

Table-2:-Bs-300 Mindray model auto analyzer.

Sample id: 40803 data type: reaction data sample type: human serum

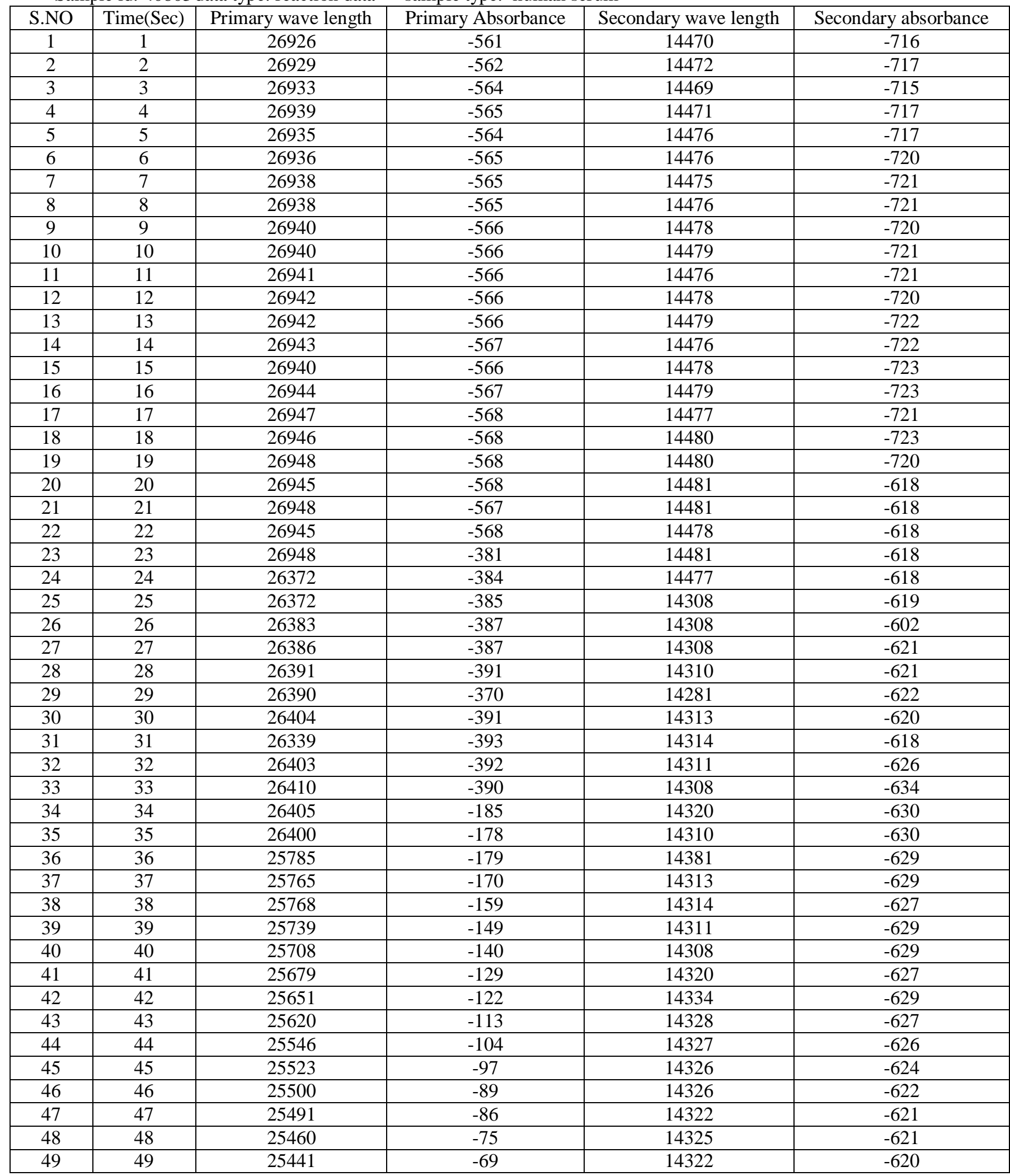


In this experiment the time when the reagent is added is $t=20 \mathrm{sec}$

The time when the sample is added is $\mathrm{t} 2=22 \mathrm{sec}$

The reaction starts when they are mixed. At $\mathrm{t} 3=47 \mathrm{sec}$ the reaction reaches the equilibrium and the absorbance reading is taken. The reaction time is $\mathrm{t} 3-\mathrm{t} 2=47-22=25 \mathrm{sec}$

\section{Graphs:-}

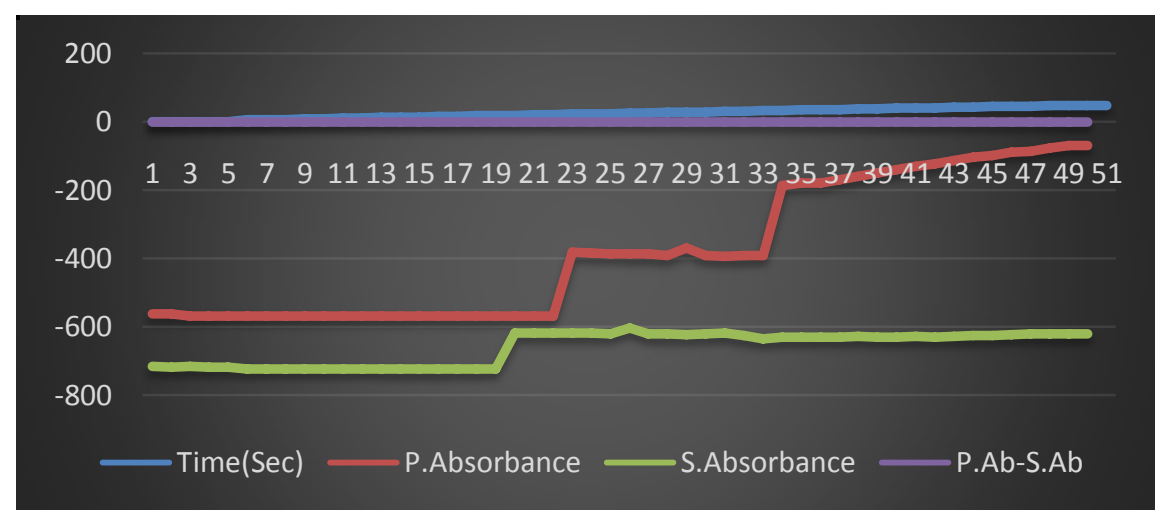

Graph 1:- Response of Creatinine Absorbance with two diffent interference filters.

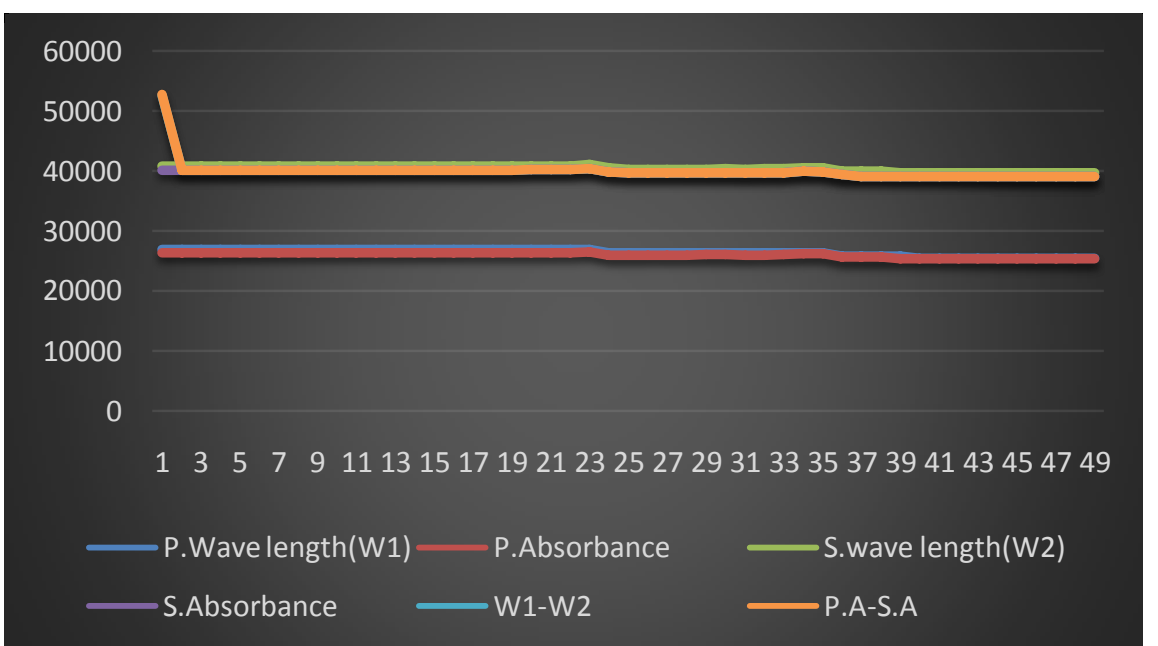

Grapgh:2:- Chart showing the variation of AbsorptionVs. Primary, Sec Wavelengths

\section{Conclusions:-}

From the above observations it is concluded that by using optical spectrometry using tungsten halogen lamp as source and interference filters the creatinine absorption characteristics by UV light were observed. Moreover the reaction time for measuring creatinine was found to be 25 seconds and response of reaction mixture is at absorption of $501 \mathrm{~nm}$. 


\section{References:-}

1. Myers GL, Miller WG, Coresh J, et al. Recommendations for improving serum creatinine measurement: A report from the Laboratory Working Group of the National Kidney Disease Education Program. Clin Chem. 2006; 52:5-18.

2. National Kidney Foundation. K/DOQI clinical practice guidelines for chronic kidney disease: evaluation, classification and stratification. Kidney Disease Outcome Quality Initiative. Am J Kidney Dis. 2002; 39:S1S246.

3. Welch MJ, Cohen A, Hertz HS, et al. Determination of serum creatinine by Isotope dilution mass spectrometry as a candidate definitive method. Anal Chem. 1986; 58:1681-5.

4. Stokes P, O'Connor G. Development of a liquid chromatography-mass Spectrometry method for high-accuracy determination of creatinine in Serum. J Chromatograph B Analytic Techno Biomed Life Sci. 2003; 794:125-36.

5. Owen LJ, Wear JE, Keevil BG. "Validation of a liquid chromatography Tandem mass spectrometry assay for serum creatinine and comparison with Enzymatic and Jaffe methods". Ann Clin Biochem. 2006; 43:118-23.

6. J E Haddow, G J Knight, G E Palomaki, L M Neveux and BA Chilmonczyk "Replacing creatinine measurements with specific gravity values to adjust Urine cotinine concentrations". Foundation for Blood Research, Scarborough, ME 04070-0190.

7. Mathew TH. "Australasian Creatinine Consensus Working Group. Chronic Kidney disease and automatic reporting of estimated glomerular filtration Rate: a position statement"Med J Aust. 2005; 183:138-41.

8. Levey AS, Coresh J, Greene T, et al. "Expressing the MDRD study equation for estimating GFR with IDMS traceable (gold standard) serum creatinine Values" J Am Soc Nephron. 2005; 16:69A.

9. Edmund J. Lamb, Andrew S. Levey, and Paul E. Stevens The Kidney Disease Improving Global Outcomes (KDIGO) Guideline Update for Chronic Kidney Disease: Evolution not Revolution, Clinical Chemistry 2013; v. 59, p.462-465.

10. M.Sreedhar, Dr.P.L.H.Varaprasad, Dr.A.Bhujangarao, M.Saradadevi, Absorption studies of creatinine using kinetic reaction method by optical interference wavelength filters. International journal of scientific and engineering research publications ISSN 2229-5518 vol.6 issue 2, February 2015, page nos 148 to 153, Country: France (Impact factor 2013-14: 3.2).

11. M.Sreedhar, Dr.P.L.H.Varaprasad, Dr.A.Bhujangarao M.Saradadevi Absorption studies of creatinine using End-point Method by optical interference wavelength filters. International journal of scientific and research publications ISSN 2250-3153 vol.5, issue 2, page nos:1 to 4, Country: Joint collaboration between USA \& India, February 2015(Impact factor 2013:1.22).3. International journal of applied engineering research ISSN 0973-4562 vol.6 